\title{
ADOÇÃO POR CASAIS DO MESMO SEXO: RELATOS DE PSICÓLOGOS DO JUDICIÁRIO ${ }^{1}$
}

\author{
Flávia Ximenes \\ Pontifícia Universidade Católica de Campinas. \\ Fabio Scorsolini-Comin \\ Universidade Federal do Triângulo Mineiro
}

\begin{abstract}
Resumo
Este estudo exploratório teve como objetivo investigar concepções de psicólogos que atuam no Judiciário acerca da adoção por casais do mesmo sexo. Participaram quatro psicólogos que atuam em Tribunais de Justiça dos Estados de Minas Gerais e São Paulo. As entrevistas semiestruturadas foram audiogravadas, transcritas, analisadas vertical e horizontalmente. Categorias encontradas: formação profissional; compreensão sobre a adoção; contato com processos de adoção por casais do mesmo sexo; perspectivas sobre a adoção por casais do mesmo sexo e a atuação da Psicologia nesse contexto. Três dos participantes já tiveram contato com esses processos de adoção. As principais dificuldades foram a escassez de conhecimentos e o preconceito que permeia o sistema judiciário no Brasil. Conclui-se que profissionais necessitam não apenas de formação específica sobre a área e a temática, mas também reflexão constante acerca de suas práticas, o que pode orientar os currículos em cursos de graduação e pósgraduação em Psicologia.
\end{abstract}

Palavras-chave: Homoparentalidade; Adoção; Psicologia Jurídica; Atuação do Psicólogo.

\section{ADOPTION BY GAY COUPLES: REPORTS FROM PSYCHOLOGISTS OF JUDICIARY}

\begin{abstract}
This exploratory study had as an objective investigating the conceptions of psychologists that act in the judiciary about adoption by same-sex couples. Four psychologists that work in Law Courts of the States of Minas Gerais and São Paulo participated. The semi structured interviews were recorded, transcribed, vertically and horizontally analyzed and categorized. Found categories: professional formation; comprehension about adoption; contact with processes of adoption by same-sex couples; perspectives about adoption by same-sex couples and the role of Psychology in this context. Three of the participants had already gotten in touch with those adoption processes. The main difficulties were the lack of knowledge and the prejudice that permeates the judiciary system in Brazil. It's concluded that professionals need not only specific formation about the area and the subject, but also constant reflection about their practices, what may guide the curriculum in undergraduate and graduate courses in Psychology.
\end{abstract}

Keywords: Homoparenthood; Adoption; Juridical Psychology; Psychologist Role.

${ }^{1}$ Este artigo é decorrente da monografia de conclusão de curso de Flávia Ximenes, orientada pelo Prof. Dr. Fabio Scorsolini-Comin, intitulada: Adoção por casais do mesmo sexo: relatos de profissionais da Psicologia que atuam no Judiciário". Este trabalho recebeu o Prêmio Silvia Lane de Melhor Monografia na área de Psicologia no ano de 2014 (8 $8^{a}$ edição). 


\title{
ADOPCIÓN POR PAREJAS HOMOSEXUALES: RELATOS DE PSICÓLOGOS DE LA JUSTICIA
}

\begin{abstract}
Resumen
Este estudio exploratorio tuvo como objetivo investigar los conceptos de psicólogos que actúan en los Tribunales de Justicia con la adopción por parejas del mismo sexo. Participaron cuatro psicólogos que actúan en Tribunales de Justicia en los Estados de Minas Gerais y São Paulo. Las entrevistas fueron grabadas, transcritas y analizadas. Categorías: formación profesional; comprensión sobre la adopción; contacto con procesos de adopción por parejas del mismo sexo; perspectivas sobre la adopción por parejas del mismo sexo y la actuación de la Psicología en este contexto. Tres de los participantes ya tuvieron contacto con estos procesos de adopción. Las dificultades fueron la escases de conocimientos y el prejuicio solapado del sistema judicial en Brasil. Se concluye que los profesionales no solo necesitan la formación específica sobre esta área y la temática, sino que también una reflexión constante sobre sus prácticas, lo que puede orientar los currículos en cursos de graduación y post graduación en Psicología.
\end{abstract}

Palabras claves: Homoparentalidad; Adopción; Psicología; Actuación del Psicólogo.

\section{INTRODUÇÃO}

Entre as diversas mudanças na organização familiar observadas na contemporaneidade, destaca-se a assunção de novas demandas de parentalidade, como a busca pela autorização legal à adoção de crianças por casais do mesmo sexo. Antes desse cenário, predominavam famílias homoparentais formadas com filhos trazidos de relacionamentos anteriores ou mesmo adotados por apenas um dos companheiros (Amazonas \& Braga, 2006; Fonseca, 2008). Com o avanço das tecnologias e maior aceitação da comunidade em geral, muitos casais homoafetivos têm buscado meios de acesso à parentalidade a partir da reprodução assistida e também da adoção legal (Zambrano, 2015). Este estudo debruça-se especificamente sobre os casos nos quais os casais do mesmo sexo procuram a adoção de uma criança ou adolescente como forma de exercício da parentalidade.

\section{Adoção por casais do mesmo sexo}

A discussão a respeito dos direitos dos homossexuais tem se ampliado no cenário brasileiro em função de marcos considerados recentes, como o reconhecimento da união civil entre pessoas do mesmo sexo no ano de 2011 e a proibição dos cartórios de todo o país a se recusarem a realizar o casamento civil entre pessoas do mesmo sexo, em 2013, pelo Conselho Nacional de Justiça. Outros marcos referem-se a projetos de lei já arquivados que tratam da criminalização da homofobia e das práticas psicológicas relacionadas à orientação sexual e afetiva. No Brasil, não há qualquer restrição legal quanto à orientação sexual ou ao estado civil do adotando, porém as dificuldades são muito mais de ordem moral do que legal (Cecílio, Scorsolini-Comin, \& Santos, 2013; Futino \& Martins, 2006; Santos, Scorsolini-Comin, \& Santos, 2013). A questão do direito à parentalidade homossexual aparece como pauta de discussões no mundo todo, principalmente relacionada ao direito à adoção. 
A Constituição Federal do Brasil, a respeito dos direitos e deveres individuais e coletivos, destaca, em seu artigo 50, que "todos são iguais perante a lei, sem distinção de qualquer natureza" (Brasil, 1988). Portanto, de acordo com a lei máxima vigente em nosso país, é inconstitucional discriminar qualquer pessoa baseada em sua orientação sexual. Também o direito à adoção entra nesta discussão, pois negar este direito a um casal ou um cidadão homossexual baseada neste critério é ir contra o direito da igualdade. O Código de Ética dos profissionais da Psicologia apresenta como princípios fundamentais o respeito e a promoção da igualdade e da liberdade do ser humano. O seu trabalho deve promover qualidade de vida e contribuir para eliminar quaisquer formas de discriminação ou opressão. De acordo com o artigo $2^{\circ}$, ao psicólogo é vedado praticar ou ser conivente com quaisquer atos de discriminação e induzir convicções políticas, morais, ideológicas, religiosas, de orientação sexual ou a qualquer tipo de preconceito, quando do exercício de suas funções profissionais (Conselho Federal de Psicologia [CFP], 2005). Aos psicólogos, portanto, não cabe promover julgamentos de valor a respeito da orientação sexual ou mesmo da possibilidade ou não da adoção por casais homoafetivos. O que é necessário, para todos os casos, é a realização de uma avaliação que identifique possíveis benefícios ou prejuízos à criança adotada, o que não tem relação direta com a orientação sexual dos postulantes.

Discute-se muito sobre o desejo de homossexuais terem filhos, visto que, pela assunção de sua própria identidade sexual, espera-se que haja a prerrogativa de não terem filhos, pela incapacidade biológica do casal (Uziel, 2007). Entretanto, é cada vez mais comum ouvirmos relatos de profissionais ou mesmo na mídia, de casos de homossexuais que lutaram para terem seus filhos e os registrarem com os nomes do casal, como pais ou mães daquela criança, na busca por um direito à cidadania, ao exercício da parentalidade e à visibilidade desse arranjo familiar (Lira, Morais, \& Boris, 2016).

O termo homoparentalidade, originado na França, é utilizado para nomear relações de parentalidade exercidas por homens e mulheres homossexuais (Cecílio, Scorsolini-Comin, \& Santos, 2013; Santos, Scorsolini-Comin, \& Santos, 2013; Zambrano, 2006; Uziel, Mello, \& Grossi, 2006). Ainda que este termo venha sendo criticado por muitos pesquisadores que o associam a uma diferenciação no exercício da parentalidade justamente centralizado na questão da orientação sexual dos pais, ainda constitui uma expressão importante, notadamente em seu aspecto político e de visibilidade (Amazonas, Veríssimo, \& Lourenço, 2013), que vem ganhando cada vez mais destaque na contemporaneidade.

Apesar dos avanços nas discussões sobre a temática, a realidade brasileira atual mostra que é necessário um investimento maior no campo da Psicologia (Silva, 2008). Uma das questões mais discutidas quando se fala nessa nova configuração familiar é a questão da criação dos filhos. Confunde-se sexualidade 
e função parental e a principal dúvida que permeia a discussão é em relação à identificação que a criança tem com os pais. No caso de pais homossexuais, o receio, muitas vezes, é o de que a criança ou adolescente seja influenciada pela orientação sexual dos mesmos, identificando-se com a homossexualidade dos genitores (Castro, 2008; Silva, 2008), o que se mostra controverso até mesmo dentro de algumas abordagens psicológicas, como a psicanálise (Zambrano, 2006). Esta discussão, por vezes, resvala em concepções cristalizadas acerca da identificação de gênero e apresenta a orientação sexual como uma preocupação normatizadora, associando-a a algo que deva ser combatido e prevenido - o que ressoa no preconceito, na discriminação, na exclusão e na patologização dos comportamentos e expressões sexuais, notadamente daqueles que fogem à heteronormatividade (Araújo, Oliveira, Sousa, \& Castanha, 2007; Lira, Morais, \& Boris, 2016; Pereira, Torres, Falcão, \& Pereira, 2013).

Embora estudos científicos demonstrem que não há relação unívoca entre a orientação sexual dos pais e a dos filhos, nem mesmo diferenças em termos desenvolvimentais de crianças criadas por pais homossexuais ou heterossexuais (Amazonas, Veríssimo, \& Lourenço, 2013), muitos profissionais responsáveis pela autorização da adoção (Poisson, 2001) podem compartilhar dessas concepções que associam a homossexualidade dos genitores a práticas educativas parentais que não são consideradas adequadas ou mesmo que podem gerar prejuízos desenvolvimentais em crianças e adolescentes. Estudos realizados nos Estados Unidos verificaram que não há diferenças no desenvolvimento psicológico e escolar de crianças inseridas em famílias homoparentais e mesmo em relação à adaptação social, em comparação a famílias chamadas "convencionais" ou mesmo consideradas "tradicionais", centralizadas no modelo de pais heterossexuais e seus filhos (Gomes, 2003, citado por Silva, 2008). Castro (2008) afirma que a função parental não está contida no sexo, nas práticas sexuais ou na orientação afetiva, mas no modo como os adultos cuidadores lidam com questões relativas às práticas educativas, como poder, hierarquia, disciplina, comportamentos e tomada de decisão, ou seja, elementos que não se relacionam à sexualidade dos pais.

Atuação do psicólogo no campo jurídico e a questão da adoção por casais do mesmo sexo

Os olhares avaliativos dos profissionais das áreas psicológicas, sociais e jurídicas pode gerar autocobranças infindáveis por parte dos pais, causando sofrimento psíquico (Silva, 2008). O peso de serem homossexuais adotando uma criança é muito maior e vem acompanhado de vigilância e cobranças extremas. O fato de ter um filho consanguíneo ou por adoção modifica completamente a dinâmica familiar e é necessária uma avaliação criteriosa dos candidatos a pais, visando a identificar a motivação e disponibilidade para a filiação. O Estatuto da Criança e do Adolescente (ECA) aponta que a adoção somente deve ser indicada 
após verificarem-se reais vantagens para o adotado nas esferas pessoal, moral e afetiva (Futino \& Martins, 2006).

Um estudo realizado no Brasil com psicólogos clínicos fornece a ideia de como essa demanda social vem sendo tratada (Perroni \& Costa, 2008). O objetivo era perceber como esses profissionais compreendiam o exercício da homparentalidade por casais do mesmo sexo e os resultados obtidos demonstraram que a maioria dos profissionais acredita que mais importante que a orientação sexual do casal é o preparo dos mesmos para educar os filhos seus valores, comprometimento, responsabilidades e qual o espaço para essa criança em suas vidas. Também é importante analisar a maturidade emocional e o modo como lidam com as dificuldades. A busca por orientação psicológica demonstra que esse casal está disposto a dar o melhor de si para essa família. E o que aparece como preocupação é a falta dos modelos masculino e feminino para o desenvolvimento psicossexual da criança (Perroni \& Costa, 2008).

Alguns estudos trazem resultados semelhantes, relatando uma opinião imparcial de profissionais da rede psicossocial em Portugal que, questionados sobre a atribuição de custódia de uma criança mediante o conhecimento da orientação sexual dos progenitores, responderam que esta deveria ser entregue ao progenitor que demonstrasse ser mais capaz, independente da orientação sexual (Gato, Fontaine, \& Carneiro, 2010, 2012). Portanto, temos distintas opiniões em diferentes contextos, o que gera a necessidade de mais estudos acerca do tema. Há que se considerar que a temática é ainda pouco investigada se comparada à importância que a atuação do psicólogo no campo jurídico vem alcançando (Costa, Penso, Legnani, \& Sudbrack, 2009; Cruz, Maciel \& Ramirez, 2005; Lago \& Bandeira, 2009).

Segundo Santos e Costa (2010), a atuação dos psicólogos jurídicos está voltada para as "intervenções realizadas nas Varas da Infância e Juventude, Varas de Família e Varas Criminais, cujos profissionais utilizam diferentes recursos teóricos e metodológicos das abordagens clínicas para realizar suas observações, visando à elaboração de relatórios que possibilitem reflexões sobre a dinâmica do sujeito e de sua família" (p. 556). A construção desse trabalho ainda não está consolidada, segundo essas autoras, haja vista as diferentes perspectivas sobre uma atuação que deve atender, ao mesmo tempo, aos objetivos solicitados pelos juízes, por exemplo, e às famílias que se encontram em sofrimento.

Compreender a formação desses profissionais e seu preparo para a avaliação e a intervenção em situações como a de adoção por casais do mesmo sexo é uma necessidade (Lago \& Bandeira, 2009). Realizar pesquisas com esses profissionais é uma forma de não apenas compreender suas concepções acerca da adoção por casais do mesmo sexo, mas justamente deflagrar de que modo eles têm sido formados para atuar diante de temáticas como essas (ScorsoliniComin, Ximenes, Meletti, \& Santos, 2015). Estariam os cursos de graduação e 
pós-graduação em Psicologia preparados para fomentar esse debate? E como ocorre a formação do psicólogo jurídico em nosso país? Em que medida os posicionamentos desses profissionais podem se refletir em práticas mais ou menos estereotipadas diante das demandas das novas famílias? Essas são algumas das perguntas que conduziram o presente estudo. A partir desse panorama, o objetivo deste estudo foi investigar as concepções de psicólogos e psicólogas que atuam no judiciário acerca da adoção de crianças e adolescentes por casais do mesmo sexo.

\section{MÉTODO}

\section{Participantes}

A amostra de conveniência foi constituída por profissionais da Psicologia que atuam no Judiciário em cidades do interior dos Estados de Minas Gerais e São Paulo. Foram entrevistados quatro profissionais, sendo três mulheres e um homem, no período de dezembro de 2012 a fevereiro de 2013. Foram incluídos profissionais que possuíam bacharelado em Psicologia havia pelo menos um ano, que atuavam como psicólogos no Judiciário havia pelo menos um ano, que estavam no pleno exercício da profissão e que consentiram em participar da entrevista por meio da assinatura do Termo de Consentimento Livre e Esclarecido. Não houve restrições em relação aos aspectos socioeconômicos dos participantes, tempo máximo de atuação na área, tempo máximo de graduação em Psicologia, nem idade máxima do participante. Esses profissionais foram contatados em duas comarcas distintas nas quais os autores possuíam pesquisas em andamento, sendo que as entrevistas foram realizadas com todos os profissionais que se disponibilizaram a participar do estudo. Como se trata de um estudo exploratório conduzido em uma perspectiva qualitativa de pesquisa, considerou-se adequado o tamanho da amostra, haja vista que a mesma permitiu com que o objetivo fosse alcançado.

Em termos do perfil da amostra, a idade dos participantes variou entre 34 e 52 anos, com média de 44,25 anos. Dois profissionais eram graduados somente em Psicologia e os outros dois em Psicologia e Direito, sendo Psicologia a primeira formação. Todos atuam em comarcas dos Estados de Minas Gerais e São Paulo. Em relação à abordagem teórica utilizada, dois profissionais relataram utilizar a psicanálise, outro utiliza a cognitivo-comportamental e um dos entrevistados não declarou essa informação. Os participantes estavam formados, em média, havia 21,75 anos. O tempo de atuação como psicólogo judiciário variou de cinco a 21 anos, com média de 12,75 anos de experiência.

\section{Instrumento}

Foi utilizado um roteiro de entrevista semiestruturado elaborado pelos pesquisadores a partir dos objetivos do estudo. Em linhas gerais, foram 
coletados dados referentes à formação profissional, ao seu entendimento sobre a homoparentalidade e à adoção por casais do mesmo sexo, bem como concepções referentes ao tema.

\section{Procedimento}

Coleta de dados. O recrutamento dos participantes deu-se por meio da rede de contatos dos pesquisadores, em duas comarcas do interior dos Estados de Minas Gerais e São Paulo. Nessa ocasião, os pesquisadores explicitaram os objetivos do estudo e os termos do trabalho. Todos os profissionais que se disponibilizaram para a pesquisa foram entrevistados. Os profissionais leram o Termo de Consentimento Livre e Esclarecido e atestaram sua anuência por meio da assinatura do referido termo. Posteriormente, foram realizadas as entrevistas. Para assegurar um ambiente de conforto físico e mental, as entrevistas ocorreram em salas reservadas de um serviço-escola. O instrumento foi aplicado face a face com os participantes, individualmente. Foi solicitada a permissão para audiogravar as entrevistas, que tiveram duração aproximada de uma hora e 30 minutos. Estas foram transcritas na íntegra e literalmente para posterior análise e interpretação dos dados.

Análise dos dados. As entrevistas foram analisadas verticalmente (uma a uma), a fim de conhecer as concepções trazidas por cada participante e, em um segundo momento, foi realizada uma análise horizontal, buscando identificar semelhanças e diferenças nos relatos de todos os participantes, em uma perspectiva mais integradora. As categorias analíticas foram construídas a partir da técnica de análise de conteúdo na modalidade temática (Campos \& Turato, 2009), que destaca a necessidade de ancoragem dos conteúdos verbalizados a partir de um quadro teórico delimitado que se situa em determinados pressupostos e paradigmas, considerando tanto a frequência como a significação atribuída aos discursos. Essa análise permitiu a construção de categorias analíticas a posteriori, condizentes com o objetivo do estudo. As categorias foram analisadas a partir de autores que tratam do tema da homoparentalidade no contexto brasileiro (Grossi, 2003; Grossi, Uziel, \& Mello, 2007; Mello, 2005a, 2005b; Uziel, 2007).

Considerações éticas

O projeto que deu origem a este estudo foi aprovado pelo Comitê de Ética em Pesquisa da universidade de origem dos autores (Protocolo n 2360/2012).

\section{RESULTADOS E DISCUSSÃO}

Após análise das entrevistas, identificamos quatro eixos principais, que emergiram como temática comum entre os entrevistados. São eles: (a) Formação profissional; (b) Compreensão sobre o conceito adoção; (c) Contato 
com processos de adoção por casais do mesmo sexo; e (d) Perspectivas dos(as) psicólogos(as) sobre a adoção por casais do mesmo sexo e a atuação da Psicologia nesse contexto. Essas categorias serão apresentadas e discutidas a seguir.

\section{Formação profissional}

A formação profissional para atuar em Psicologia Jurídica não foi pensada inicialmente como categoria de análise. Porém, a questão da insuficiência na formação profissional e a busca por outros conhecimentos para basear a atuação na área emergiu na fala de todos os profissionais entrevistados. Dois deles buscaram a formação em Direito para auxiliá-los e dois destacaram também a importância da utilização de abordagens teóricas, como a psicanálise, na realização de seu trabalho. A seguir, alguns excertos que ilustram essa dimensão:

As únicas disciplinas que talvez deram um suporte foram as disciplinas das áreas sociais. Agora, a minha atuação no Judiciário, eu considero porque que é a minha formação em psicanálise que me dá toda a minha base, eu não consigo nem imaginar profissionais atuando dentro do Judiciário sem uma formação psicanalítica. (Maria, 49)

Quando eu entrei no fórum, eu senti da dimensão da Psicologia Jurídica e acho que pra entender mais essa intersecção da Psicologia com o Direito, fui fazer Direito. (João, 52)

Não tive nenhum conhecimento sobre a Psicologia Jurídica na graduação. Conheci quando fui prestar o concurso. Não tinha nenhum professor, nem matéria específica de Jurídica. (...) Fui praticamente autodidata, pois não conhecia nada, então tive que me virar comprando livros e estudando muito. Aprendi muito com a prática e também com as colegas. (Ana, 42)

Já estando lá, por sorte eu contei com colegas de trabalho que me ajudaram muito, são pessoas que tiveram toda a paciência de explicar, de acompanhar, meio de supervisionar mesmo, mas conforme a gente vai tendo as demandas de trabalho, eu fui buscando as leituras. (Claudia, 34)

A Psicologia Jurídica recebe essa denominação por ser uma área da Psicologia que se relaciona com o sistema de justiça. Popolo (1996) afirma que se qualifica no campo da Psicologia o estudo dos comportamentos e por jurídico pode-se compreender as atividades realizadas por psicólogos que dão suporte ao campo do Direito, dentro e fora dos tribunais (França, 2004). Por ser uma área ainda pouco explorada no Brasil, há escassez de material teórico para embasar a prática dos profissionais, o que é confirmado pela fala dos entrevistados. Para tanto, muitos procuram embasar sua prática no campo do Direito, o que é benéfico para a construção do trabalho. Segundo França (2004), não há problema para a Psicologia Jurídica responder às perguntas e demandas do jurídico, porém sua atuação deve transcender suas solicitações, não ocorrendo uma estagnação nessa relação, embasando seu trabalho do ponto de vista 
psicológico e respondendo às perguntas que lhe são lançadas, em uma relação de complementaridade. A Psicologia Jurídica produz conhecimentos relacionados ao campo do Direito e é benéfico que haja um diálogo, mas não uma interposição dos conhecimentos. O despreparo na formação apareceu, inclusive, como influência negativa na avaliação de casos de adoção por casais do mesmo sexo, especificamente na fala de João:

Foi a minha primeira experiência, meu primeiro caso e eu, tipo assim, não tava preparado. Eu confesso que os primeiros relatórios eu fiz com uma certa insegurança, meio em cima do muro, ainda sem ter muito referencial pra poder... E acho que o juiz acabou negando. (João, 52)

Há que se considerar que a discussão em torno da adoção por casais do mesmo sexo é ainda considerada recente em nosso país (Manzi-Oliveira, 2009). Embora haja um crescente interesse no tema, são poucos os profissionais que já se depararam com a avaliação desses casos. A atenção a essa nova demanda, no caso de João, fez com que ele não apenas buscasse informações e conhecimentos a respeito, como também se sentisse diretamente responsável pelo resultado negativo de um pedido de adoção no qual ele atuou. As suas ferramentas para a avaliação, à época, foram compreendidas como insuficientes, gerando desconforto e sentimento de "culpa" pelo indeferimento do pedido. No estudo de Lago e Bandeira (2009), foi constatado que os profissionais de Psicologia conhecem a maioria das recentes demandas em relação ao Direito de Família, mas que tais assuntos ainda não suficientemente cotejados nos cursos de Psicologia.

Essas dificuldades na formação acabam impactando diretamente o trabalho desses profissionais, de modo que se deve considerar não apenas o escasso acesso a instrumentos e protocolos de avaliação nesses casos, mas também a ausência de reflexões que possam nortear a atuação diante desse cenário. Desse modo, não se trata de diferenciar esses casais no processo de avaliação, mas de possibilitar que haja uma discussão acerca dessa demanda cada vez mais presente no cenário jurídico. Como realizar essas avaliações? Como propor essas reflexões? Essas são questões emergentes nas falas dos profissionais e parecem atravessar o modo como se posicionam quando são acionados para realizar tais avaliações psicossociais dos postulantes.

Como o trabalho da Psicologia Jurídica requer o entendimento dos fenômenos psicológicos no contexto da Justiça na interface com o Direito, os profissionais devem buscar qualificação profissional constantemente, notadamente em relação a novas demandas (Cruz, Maciel, \& Ramirez, 2005; Santos \& Costa, 2010). É nesse sentido que a segunda graduação em Direito, no caso de dois entrevistados, foi compreendida como a possibilidade de formação e atualização, haja vista a insuficiência de formação da Psicologia nesse campo, segundo os participantes. A graduação em Direito respondeu, dessa forma, às 
lacunas de formação identificadas no curso de Psicologia. No entanto, destaca-se que essa atualização pode e deve ocorrer também no domínio da ciência psicológica. As universidades, tanto na graduação como na pós-graduação em Psicologia, devem estar atentas a esses movimentos e incorporar em seus currículos e projetos de pesquisa e extensão espaços para tais discussões e atualizações, em um diálogo interdisciplinar perene.

Reforça-se, de modo complementar, que se trata de uma questão ainda considerada polêmica e que gera diversos embates, de modo que a necessidade de maior formação e informação pode deflagrar possíveis dificuldades desses profissionais se posicionarem diante do tema e exercerem seu ofício de modo ético e embasado em pressupostos científicos e legais. Destacar a falta de formação para atuar nesse contexto pode, em alguns casos, obscurecer a dificuldade de entrar em contato com esses casais e promover uma escuta empática e que respeite a diversidade, operando a necessidade de um respaldo externo - científico e legal - para suas decisões, indicações ou recomendações nos processos de avaliação psicossocial. De qualquer modo, uma formação mais qualificada nesse campo pode promover incrementos e maior isonomia no modo como esses casais são recebidos e avaliados no processo de postulação à adoção.

\section{Compreensão sobre o conceito de adoção}

Nesta categoria, buscamos compreender a concepção dos profissionais sobre o significado da adoção. Pode-se perceber no contexto das entrevistas que o conceito de adoção é comparado ao modelo normativa de filiação, o modelo biológico. Porém, enfatizam a necessidade de uma preparação dos pais para receber uma criança que vem de um contexto familiar e social diferente, o que necessitará da adaptação de ambos e, principalmente, do esforço desses pais em prover condições satisfatórias, visando sempre ao bem-estar físico e mental da criança adotada.

Uziel (2007) destaca os medos em relação à adoção devido ao desconhecimento das origens e à hierarquia existente no meio social e cultural entre filiação consanguínea ou por adoção, o que também justifica os fantasmas em torno da adoção por casais do mesmo sexo, considerada não natural. Essa pluriparentalidade ainda é considerada instável e ameaçadora, justamente por esbarrar na soberania no biológico e do natural (Pennings, 2011; Tasker, 2005).

Idealizadamente, seria uma ação de paternagem/maternagem de uma criança ou adolescente, onde o adotante exerce todas as funções iguais de pais biológicos. Pega para educar, criar, amar, acolher, proteger, garantir o bem-estar, a fim de favorecer 0 desenvolvimento das potencialidades do ser humano. (Ana, 42)

A adoção, ela traz concretamente a visão de que olha, você aceitar essa criança como seu filho é você aceitar uma história diferente, que vem de uma outra família que não é a sua, que muitas vezes não vai ser parecido com você, apesar que as crianças ao longo do tempo a gente acha que ela vão se parecendo com os pais que adotaram, mas 
é você ter muito claro isso - você vai receber uma criança como seu filho, ou seja, você não ta adotando, você ta tendo um filho [...] é pensar nessa questão que envolve o ter filhos, as responsabilidades, a sua disponibilidade... Estar pronto pra aceitar quem é diferente de você. (Claudia, 34)

É mais fácil conceber o que não é adoção, né? Não seria adoção aquelas pretensões pra se ter um filho para preencher um espaço de uma demanda biológica que não ocorreu, em contrapartida, eu poderia dizer que a adoção é aquele ato involuntário onde as pessoas decidem por uma ideologia (...) adotarem uma criança para satisfazer as necessidades dessa criança. (Maria, 49)

Pra mim a adoção é essa pessoa, esse indivíduo querer, de fato, ser pai ou mãe e por um motivo qualquer, se algum problema de infertilidade, ou seja, pela pessoa solteira ou por alguma questão de homossexualidade, por exemplo, essa pessoa se vê inviável ou restrita, no caso da infertilidade, de ter um filho natural, biológico, então eu vejo a adoção, tipo assim, como um meio, como uma possibilidade de uma pessoa independente de gênero e estado civil, exercer a parentalidade, ser pai ou ser mãe realmente, seria uma outra possibilidade. (João, 52)

Os profissionais falam em funções parentais, que seriam ações de responsabilidade dos pais, independente de serem biológicos ou adotivos, que fazem parte do estereótipo do cuidado com crianças. Uma das profissionais que ainda não teve experiência em avaliar um casal homossexual traz a discussão sobre a diferenciação de papéis, o que atinge diretamente os casais do mesmo sexo que buscam a adoção, pois alguns profissionais, mesmo que indiretamente, buscam identificar no casal aquele que vai exercer uma função mais relacionada ao cuidado e quem terá um papel mais relacionado à educação e imposição de limites, não possibilitando a multiplicação de sentido nas famílias, trazendo novamente uma comparação com o modelo normativo, biológico.

A homossexualidade remete à ideia de negação da natureza e da paternidade em função de uma escolha de parcerias do mesmo sexo, impossibilitando a procriação, o que justifica o estranhamento em relação à parentalidade gay. São consideradas opções excludentes, como se, ao assumirem sua homossexualidade, também assumissem sua infertilidade (Uziel, 2007). A autora ainda faz questionamentos que podem auxiliar nessa discussão: qual o sentido de falar em parentalidade homossexual? E qual a pertinência desse termo? Tais questionamentos nos remetem à necessidade de realizar essa diferenciação, embasada apenas no critério da sexualidade.

Porém, da mesma forma que os heterossexuais, gays e lésbicas também são socializados no mesmo conjunto de valores, aprendendo da mesma forma a conferir importância fundamental à dimensão afetivo-sexual, a partir da conjugalidade, denotando grande responsabilidade ao parceiro por sua felicidade individual. Contrariando as concepções heterocêntricas, homossexuais buscam na vida conjugal reassegurar seus direitos, reivindicando da sociedade e do 
Estado direitos decorrentes do estabelecimento de vínculos afetivo-sexuais duradouros (Mello, 2005a; Uziel, 2007, 2012).

Fica uma fantasia de que a gente tem que identificar no casal quem é que vai ocupar o lugar de mãe e quem vai ocupar o lugar de pai, sabe? É uma fantasia que fica e que passa, às vezes, na minha cabeça também. (Claudia, 34)

O casal homossexual é enquadrado em uma dupla "deficiência": além da questão da sexualidade, falta um. Esses pais e mães sofrem pressão por serem vistos em constante débito com a família, necessitando se enquadrar em papéis específicos e definidos socialmente. É premente a necessidade de profissionais que os auxiliem nesse processo, entre eles os psicólogos, porém as cobranças são infindáveis, visto que a referência é um ideal inatingível (Uziel, 2007).

É fundamental que os profissionais de Psicologia possam refletir sobre suas concepções em relação à família, o que pode contribuir para abordagens mais coerentes com esses casais e que, de fato, os ajudem em suas dificuldades. Possibilitar a audiência da ampliação dos significados acerca do ser família é um processo que pode impactar positivamente não apenas o processo de avaliação psicossocial especificamente a partir da demanda de casais do mesmo sexo, mas também outros protocolos e atendimentos realizados por esses profissionais envolvendo diversas temáticas com as quais entram em contato em seu cotidiano. Como uma limitação na presente categoria, há se considerar que buscar as compreensões desses profissionais acerca do que é adoção acaba sendo um processo que recupera elementos essencialmente técnicos, embasados em referenciais científicos e legais dominados por esses profissionais, o que pode obscurecer o acesso às concepções pessoais dos mesmos acerca da filiação adotiva e também da parentalidade e da conjugalidade em casais do mesmo sexo.

\section{Contato com processos de adoção por casais do mesmo sexo}

Nesta categoria, analisamos as experiências de dois profissionais que avaliaram diretamente casos de adoção por casais do mesmo sexo. Como o estudo buscava compreender concepções e experiências envolvendo esses casais, não foi adotado como critério de inclusão ter participado de um processo de avaliação psicossocial de casal do mesmo sexo.

Apesar de todas as dificuldades enfrentadas pelos profissionais que realizam as avaliações e por mais difícil ou injusto que o processo possa ser considerado por estar sujeito a percepções subjetivas, há que se demarcar pontos importantes a serem observados nos requerentes para nortear as avaliações. Os profissionais apontam como norteadores a capacidade de lidar com frustração, flexibilidade, saber lidar com situações difíceis, disponibilidade afetiva e capacidade para estabelecer vínculos (Uziel, 2007). As experiências dos entrevistados podem ser compreendidas a partir dos trechos a seguir: 
(...) isso me alertou pra poder procurar mais, conversar mais sobre isso, me interessar mais sobre o tema e aí eu tava mais nessa ala, eu tinha mais elementos, mais instrumental pra avaliar uma adoção por casal homossexual. E aí tinha o trabalho, nós trabalhamos juntos, fomos na casa deles mais de uma vez, conversar, conhecer o ambiente, enfim, tudo (...). (João, 52)

Elas foram avaliadas como um casal, o ambiente e o contexto familiar foram avaliados, porque precisamos ver como elas vão acolher a criança e a disponibilidade de exercer a função de pais. Analisamos também em relação às idealizações e o lugar que essa criança vai ocupar na família. (...) Acho que a dificuldade, nesse caso, é mais cultural, de um misticismo, um tabu a ser quebrado (...) Acho que os próprios homossexuais têm medo de serem barrados pelo Judiciário. Por isso, preferem adotar como solteiros, mas é uma grande perda para o companheiro e para a criança, principalmente. (Ana, 42)

É possível identificar a partir da fala dos profissionais que há um preconceito velado em relação a adotantes solteiros, principalmente do sexo masculino. $O$ fato de ser um homem solteiro acaba gerando uma inquietação nos profissionais que fazem a avaliação devido a um pré-conceito cultural que o cuidado com uma criança está relacionado ao feminino e pressupõe-se uma orientação homossexual. Também demonstram receio quanto a abusos físicos e sexuais.

As crenças a respeito da homossexualidade são culturalmente instauradas, gerando representações sociais diversas a respeito da adoção, dos homossexuais e também do exercício da parentalidade por casais do mesmo sexo (Araújo et al., 2007). O estudo de Pereira et al. (2013), com estudantes universitários, classificou três tipos de representações sociais referentes à explicação da homossexualidade: (a) as relacionadas aos fatores biológicos; (b) as relacionadas à natureza da homossexualidade baseada em conceitos religiosos, ético-morais e psicológicas, representações essas associadas a comportamentos discriminatórios; (c) as relacionadas a fatores culturais, envolvendo menor discriminação. Assim, pode-se compreender que determinadas representações sociais podem estar mais ou menos associadas a comportamentos de discriminação e preconceito, bem como a aspectos protetivos e promotores de desenvolvimento, elementos esses que se cravam em práticas e discursos (Souza, Moscheta, Casarini, \& Scorsolini-Comin, 2016). Ainda em relação a esse processo, a literatura também observa a existência da crença de que pais homossexuais incentivariam a orientação sexual dos filhos ou que os sujeitariam a viver em ambientes imorais (Uziel, 2007), em uma clara confusão entre sexualidade e função parental (Zambrano, 2015), patologizando as expressões sexuais não hegemônicas. O que deve ser questionado, entretanto, é se aquela família e a relação constituída será boa para o adotado naquele momento, promotora de desenvolvimento, se trará reais benefícios para a criança ou adolescente. 
No setor mesmo, assim, a gente já depara com alguns comentários "ah, mas tá querendo adotar?" (...) Eu já ouvi comentário, tipo assim: "Ah, mas sozinho? Tem uma orientação homossexual e quer adotar um adolescente? Mas quem me garante que não é pra abuso? Quem me garante que não é pra fazer uso?" Entendeu? (Maria, 49)

Há uma articulação entre maternidade e feminilidade e, contraposto a isso, um distanciamento da masculinidade e paternidade, pois tal papel é muito mais vinculado à sexualidade e, por consequência, à promiscuidade, gerando, assim, uma série de suspeitas com relação a homens que se proponham a adotar sozinhos (Uziel, 2007). Apesar de não haver uma regulamentação específica do Estatuto da Criança e do Adolescente com relação a critérios objetivos de preferência entre candidatos, os próprios profissionais demarcam alguns critérios subjetivos e, devido a isso, alguns autores reforçam a criação de uma sequência de predileção em relação aos pais, dando preferência, por exemplo, a casais heterossexuais casados ou em união estável sobre os solteiros, domiciliados no Brasil sobre os domiciliados no exterior, quem não tem filhos sobre os que já os têm, entre outras especificidades (Uziel, 2007).

A busca pela constituição de uma família considerada tradicional e heterossexual atravessa, desse modo, a atuação de alguns profissionais da Psicologia no judiciário, operando-se não apenas a discriminação de postulantes à adoção que fujam desse perfil como também a sedimentação de uma prática que não dialoga com os novos arranjos familiares e com as mudanças sociais e culturais observadas na contemporaneidade. Fortalecer a necessidade de diálogo constante acerca desses aspectos é um dos elementos que podem nortear mudanças na formação em Psicologia, especificamente na área da Psicologia Jurídica, assim como mencionado em outras investigações (Lago \& Bandeira, 2009; Santos \& Costa, 2010).

Perspectivas dos(as) psicólogos(as) sobre a adoção por casais do mesmo sexo e a atuação da Psicologia nesse contexto

Buscamos compreender nesta categoria a visão que os profissionais têm de seu papel a respeito desta temática. Em duas entrevistas, surgiu a preocupação dos profissionais com relação a seu papel nas avaliações para a adoção, pois apesar de se pautarem em técnicas confiáveis, são consideradas por elas também muito subjetivas. Destacam a grande pressão que sentem sobre decidir os destinos, tanto das crianças, quanto dos requerentes à adoção. O processo de avaliação de adoção é permeado por pressão e inseguranças e, da mesma forma que os profissionais têm de cuidar para não fundar um parecer desfavorável em seus preconceitos, sejam eles de qualquer espécie, também aparece a preocupação inversa e esses profissionais correm o risco de terem essa escuta prejudicada pelo medo de serem preconceituosos (Uziel, 2007). 
A gente também fica num limite, às vezes quando eu chego no meu trabalho, eu penso: "Nossa, parece que eu me sinto Deus, né?!" (João, 52)

Poxa vida né, que direito que a gente tem de falar pro outro que vive uma vida em conjunto tão bem, falar que ele não tem direito a ter um filho, assim, a gente não tá nesse lugar, a gente já não é juiz, e que dirá também juiz dizer pro outro que você não pode fazer isso, né? Eu acho que é se colocar no lugar de Deus, sabe? (Claudia, 34)

Atualmente, vivenciamos um momento social de desconstrução de certos preconceitos historicamente associados aos homossexuais, tanto masculinos quanto femininos. Por meio da constituição de casais homossexuais, além de se desvincularem de representações sociais por vezes consideradas pejorativas, também reivindicam o direito de constituírem famílias, inclusive a partir da maternidade/paternidade (Mello, 2005b).

Os profissionais destacam também que a minoria dos casos com que trabalham na área de Psicologia Jurídica é de adoção. É importante salientar que, em muitos casos, pensando na situação familiar vivida anteriormente pela criança como de intenso sofrimento, os profissionais utilizem o discurso do "mal menor", ou seja, as crianças "mais difíceis", que possuem vivências de sofrimento enraizadas, são combinadas a candidatos a pais que não correspondem ao modelo familiar idealizado, incluindo aqui os casais homoafetivos (Uziel, 2007, 2012).

Os processos dos casais que querem se habilitar para adoção são a menor demanda. Eu posso te falar que em um mês eu trabalhei mais com criança vítima de abuso sexual que adoção (...). Então se uma criança vai pra adoção, é porque na família de origem dela deu muito errado... (João, 52)

Infelizmente, casos de adoção que aparecem pra gente avaliar são em número mínimo, diria que $10 \%$. São mais comuns casos de crianças vitimizadas, disputa por guarda, brigas. (Ana, 42)

De acordo com a fala de Ana, há uma baixa procura de adotantes homossexuais devido ao preconceito, desinformação dessas pessoas sobre seus direitos e o medo de exposição e visibilidade do processo. Devido a esses aspectos, muitos ainda buscam adotar sozinhos, não como casais (Amazonas, Veríssimo, \& Lourenço, 2013; Scorsolini-Comin et al., 2015; Zambrano, 2006). Alguns setores sociais, influenciados principalmente por ideologias religiosas, têm prejudicado as famílias compostas por casais do mesmo sexo de manifestarem seus direitos, demonstrando muita resistência em aceitar os discursos da comunidade LGBT que buscam a legitimidade da vivência de sua sexualidade e constituição de famílias. Infelizmente, a homossexualidade ainda é vista como um misto de pecado, doença e crime, o que faz com que sejam constantemente atingidos por discursos e atos discriminatórios e de intolerância (Mello, 2005a). 
Eu acho que muitas pessoas nos procuram, mas eu acho que devem ter outras tantas que sequer procuram, porque já tem receio de que tem que ir até o Fórum e dizer que ainda é um casal homoafetivo, eu acho que ainda é muito tabu, sabe, pras próprias pessoas se exporem. (Claudia, 34)

Acho que os próprios homossexuais têm medo de serem barrados pelo Judiciário. Há uma grande dificuldade em falar e não ser aceito. Por isso, preferem muitas vezes adotar como solteiros, mas é uma grande perda para o companheiro e para a criança principalmente. Pai e filho ficam sem direitos jurídicos pela falta de registro e para a criança é muito ruim, pois não tem direito à pensão, herança, em caso de falecimento, fica desprotegida. (Ana, 42)

Às vezes as próprias pessoas pretendentes à adoção, que já têm uma convivência homoafetiva de muitos e muitos anos, também têm seu preconceito. Elas temem, por exemplo, ajuizar um procedimento de adoção com medo de descobrirem que têm uma escolha homoafetiva, né? (Maria, 49)

Apesar de estar previsto na Constituição Federal a inviolabilidade do direito à intimidade e à vida privada, os profissionais da Psicologia que realizam as avaliações fazem tais questionamentos visando a resguardar os direitos e o bem-estar do adotado e se julgarem pertinente à avaliação do adotante. Na maioria das vezes, exploram o que o pretendente conta espontaneamente, buscando entender os sentidos produzidos que o requerente constrói em relação à adoção (Uziel, 2007). Apesar de ser um ponto de análise e discussão, é preciso deixar claro que não há nenhuma lei que expresse claramente a permissão ou impedimento da adoção por casais homoafetivos, o que dá ainda maior abertura para interpretações pessoais, principalmente dos operadores do Direito.

As famílias homoparentais trazem à tona diferentes questionamentos para os atores que fazem parte do processo de avaliação. Segundo Uziel (2007), para os cientistas sociais, a discussão é sobre as estruturas de parentesco (Grossi, 2003); para os juristas, sobre as formas de filiação e, para os psicólogos, o desenvolvimento de crianças em famílias diferentes das consideradas tradicionais. A dificuldade e lentidão dos processos podem advir justamente da diversidade de concepções e interpretações dos atores envolvidos, trazendo prejuízos ao processo como um todo. Reconhecer as atitudes construídas acerca desses casais postulantes à adoção, que destacam também as atitudes em relação à família e aos homossexuais (Gato, Fontaine, \& Carneiro, 2012) é um processo essencial para a atuação desses profissionais no judiciário. Discutir esses aspectos na formação, supervisão, avaliação e acompanhamento desses profissionais é algo que deve ser empreendido.

\section{CONSIDERAÇÕES FINAIS}

A partir dos relatos obtidos neste estudo, podemos perceber que a insuficiência da formação em Psicologia para atuar diretamente no Judiciário 
afeta o trabalho desses profissionais especificamente. Obviamente que os achados aqui disponíveis devem ser recebidos com parcimônia, haja vista a dificuldade de serem generalizados para outras realidades. Por ser uma área relativamente nova, organizada a partir de um movimento realizado pela Associação Brasileira de Psicologia Jurídica em 1990, as discussões tornam-se ainda mais presentes. Analisando o tempo de formação em Psicologia dos entrevistados, em média 21,75 anos, podemos concluir que na época tais discussões acerca da adoção por casais do mesmo sexo ainda não eram realizadas, dificultando a realização das avaliações dos primeiros casos. Até mesmo a discussão mais ampla sobre os processos de adoção tem sido empreendida, como ocorreu a partir da nova lei da adoção, promulgada em 2009. Devido a isso, há uma busca por outros conhecimentos que embasem a atividade prática dos profissionais, seja na busca por conhecimentos específicos relacionados ao Judiciário e ao Direito, seja por uma abordagem psicológica que possibilite formas de compreensão das situações vivenciadas no cotidiano profissional.

Os resultados do presente estudo sugerem também que os profissionais não fazem uma distinção aparente no tocante à adoção de crianças por homossexuais ou heterossexuais, mas ainda existem questões permeadas de certo preconceito, principalmente relacionadas a estereótipos sexuais, como a visão de imoralidade que ainda cerca principalmente homossexuais masculinos. Apesar de não haver explicitamente formas de discriminação, pode-se perceber a prevalência de um discurso heterocêntrico, no qual se dá a preferência de adoção às famílias formadas por casais heterossexuais, prevalecendo o discurso heteronormativo. Mas esse preconceito nem sempre é assumido claramente pelos profissionais, que destacam o preconceito dos próprios homossexuais em se exporem ao postular a adoção. O que se observa, desse modo, é a complexidade que envolve a temática, o que não atravessa apenas a consideração dos direitos dos casais do mesmo sexo e a necessidade de revisão acerca das leis que regulamentam a adoção, mas também de uma mudança maior que, inclusive, atinge a formação de profissionais para atuar nesse contexto em transformação.

O sistema judiciário está sujeito às interpretações de seus atores e, portanto, a questão da homoparentalidade ainda necessita de maior embasamento teórico e prático. A partir de uma prática psicológica embasada em técnicas coerentes, abrem-se novos caminhos para possibilitar mudanças de paradigma no tocante a essa questão, possibilitando um olhar menos diferenciado e de maior aceitação, considerando que o que importa é o bemestar do adotado, independente de questões associadas à sexualidade dos futuros pais. Cabe aos profissionais da Psicologia inseridos no Judiciário ajudar a desmistificar preconceitos e fornecer informações que possam auxiliar não 
apenas os casais que buscam a adoção e seus filhos, mas também os demais profissionais envolvidos na complexidade do tema.

Em termos das limitações deste estudo, destaca-se a reduzida quantidade de casos e a concentração dos profissionais entrevistados em comarcas de dois Estados, sendo que apenas dois entrevistados participaram efetivamente da avaliação psicossocial de casais do mesmo sexo pretendentes à adoção. Ampliar a amostra e conhecer a experiência de outros profissionais é uma proposta futura derivada das necessidades encontradas nesta investigação, o que já vem sendo conduzido em outros estudos. Promover a escuta de outros profissionais, tanto daqueles que já experienciaram a atuação em casos de adoção por casais do mesmo sexo quanto daqueles que ainda não se depararam com tal demanda mostra-se relevante no sentido de conhecer as práticas vigentes, identificar possíveis lacunas e fomentar o desenvolvimento de uma formação na área mais qualificada e atenta aos desafios da família e da sociedade na contemporaneidade. No entanto, consideramos que o exercício exploratório retratado neste estudo pode ser deflagrador de diferentes discussões entre esses profissionais e nos núcleos de formação em Psicologia, ampliando as potencialidades desta investigação tanto para a prática como para o cenário da pesquisa científica.

\section{DECLARAÇÃO DE CONFLITOS DE INTERESSE}

Os autores declaram não haver conflitos de interesse.

\section{REFERÊNCIAS}

Amazonas, M. C. L. A., \& Braga, M. G. R. (2006). Reflexões acerca das novas formas de parentalidade e suas possíveis vicissitudes culturais e subjetivas. Ágora, 9(2), 177-191.

Amazonas, M. C. L. A., Veríssimo, H. V., \& Lourenço, G. o. (2013). A adoção de crianças por gays. Psicologia \& Sociedade, 25(3), 631-641.

Araújo, L. F., Oliveira, J. S. C., Sousa, V. C., \& Castanha, A. R. (2007). Adoção de crianças por casais homoafetivos: um estudo comparativo entre universitários de Direito e de Psicologia. Psicologia \& Sociedade, 19(2), 95102.

Campos, C. J. G., \& Turato, E. R. (2009). Análise de conteúdo em pesquisas que utilizam metodologia clínico-qualitativa: Aplicação e perspectivas. Revista Latino-Americana de Enfermagem, 17(2), 124-129.

Castro, M. C. A. (2008). A adoção em famílias homoafetivas. In Conselho Federal de Psicologia (CFP), Adoção: Um direito de todos e todas (pp. 23-26). Brasília: Autor. 
Cecílio, M. S., Scorsolini-Comin, F., \& Santos, M. A. (2013). Produção científica sobre adoção por casais homossexuais no contexto brasileiro. Estudos de Psicologia (Natal), 18(3), 507-516.

Constituição da República Federativa do Brasil. (1988, 5 de outubro). Recuperado em 11 agosto 2008, de http://www.senado.gov.br/sf/legislacao/const/

Costa, L. F., Penso, M. A., Legnani, V. N., \& Sudbrack, M. F. O. (2009). As competências da Psicologia Jurídica na avaliação psicossocial de famílias em conflito. Psicologia \& Sociedade, 21(2), 233-241.

Cruz, R. M., Maciel, S. K. \& Ramirez, D. C. (2005). Apresentação. In R. M. Cruz, S. K. Maciel, \& D. C. Ramirez, (Orgs.), O trabalho do psicólogo no campo jurídico (pp. 7-8). São Paulo: Casa do Psicólogo.

Fonseca, C. (2008). Homoparentalidade: Novas luzes sobre o parentesco. Revista Estudos Feministas, 16(3), 769-783.

França, F. (2004). Reflexões sobre Psicologia Jurídica e seu panorama no Brasil. Psicologia: Teoria e Prática, 6(1), 73-80.

Futino, R. S., \& Martins, S. (2006). Adoção por homossexuais: Uma nova configuração familiar sob os olhares da psicologia e do direito. Aletheia, 24, 149-159.

Gato, J., Fontaine, A. M., \& Carneiro, N. S. (2010). Percepção de futuros profissionais de áreas psicossociais sobre o desenvolvimento psicológico de crianças educadas em famílias homoparentais. Actas do VII Simpósio Nacional de Investigação em Psicologia (pp. 1010-1023). Minho, Portugal.

Gato, J., Fontaine, A. M., \& Carneiro, N. S. (2012). Escala multidimensional de atitudes face a lésbicas e a gays: Construção e validação preliminar. Paidéia (Ribeirão Preto), 22(51), 11-20.

Grossi, M. P. (2003). Gênero e parentesco: Famílias gays e lésbicas no Brasil. Cadernos Pagu, 21, 261-280.

Grossi, M. P., Uziel, A. P., \& Mello, L. (Org.) (2007). Conjugalidades, parentalidades e identidades lésbicas, gays, travestis. Rio de Janeiro: Garamond.

Lago, V. M., \& Bandeira, D. R. (2009). A Psicologia e as demandas atuais do Direito de família. Psicologia: Ciência e Profissão, 29(2), 290-305.

Lira, A. N., Morais, N. A., \& Boris, G. D. J. B. (2016). (In)visibilidade da vivência homoparental feminina: entre preconceitos e superações. Psicologia: Ciência e Profissão, 36(1), 20-33.

Manzi-Oliveira, A. B. (2009). Adoção por casais homoafetivos: Relato de seus protagonistas. Monografia de conclusão de curso não-publicada, Faculdade de Filosofia, Ciências e Letras de Ribeirão Preto, Universidade de São Paulo, Ribeirão Preto, SP.

Mello, L. (2005a). Novas famílias: Conjugalidade homossexual no Brasil contemporâneo. Rio de Janeiro: Garamond. 
Mello, L. (2005b). Outras famílias: A construção social da conjugalidade homossexual no Brasil. Cadernos Pagu, 24(1), 197-225.

Pennings, G. (2011). Evaluating the welfare of the child in same-sex families. Human Reproduction, 26(7), 1609-1615.

Pereira, C. R., Torres, A. R. R., Falcão, L., \& Pereira, A. S. (2013). O papel de representações sociais sobre a natureza da homossexualidade na oposição ao casamento civil e à adoção por famílias homoafetivas. Psicologia: Teoria e Pesquisa, 29(1), 79-89.

Perroni, S., \& Costa, M. I. M. (2008). Psicologia clínica e homoparentalidade: Desafios contemporâneos. Fazendo Gênero 8: Corpo, Violência e Poder, 1-7. Poisson, (2001). A seleção dos candidatos à adoção: prever o imprevisível. In $\mathrm{F}$. Freire (Org.), Abandono e adoção: contribuições para uma cultura da adoção (pp. 65-66). Curitiba: Terra dos Homens.

Popolo, J. H. (1996). Psicologia judicial. Mendonza: Ediciones Juridicas Cuyo.

Santos, M. R. R., \& Costa, L. F. C. (2010). Campo psicossocial e jurídico: Relações de poder nas decisões de conflito familiares. Estudos de Psicologia (Campinas), 27(4), 553-561.

Santos, Y. G. S., Scorsolini-Comin, F., \& Santos, M. A. (2013). Homoparentalidade masculina: Revisando a produção científica. Psicologia: Reflexão e Crítica, 26(3), 575-582.

Scorsolini-Comin, F., Ximenes, F., Meletti, A. T., \& Santos, M. A. (2015). Práticas profissionais no contexto da adoção homoparental: expectativas de casais homossexuais e de psicólogos que atuam no Judiciário. In F. ScorsoliniComin, A. K. Pereira, \& M. L. T. Nunes (Orgs.), Adoção: legislação, cenários e práticas (pp. 223-237). São Paulo: Vetor.

Silva, J. R. P. (2008). A parentalidade de cara nova: Quando os homossexuais se decidem por filhos. In Conselho Federal de Psicologia (CFP), Adoção: Um direito de todos e todas (pp. 17-22). Brasília: Autor.

Souza, L. V., Moscheta, M. S., Casarini, K. A., \& Scorsolini-Comin, F. (2016). Da (im)possibilidade do diálogo: conversações públicas e os direitos LGBTs. Psicologia \& Sociedade, 28(3), 516-525.

Tasker, F. (2005). Lesbian mothers, gay fathers, and their children: A review. Developmental and Behavioral Pediatrics, 26(3), 224-240.

Uziel, A. P. (2007). Homossexualidade e adoção. Rio de Janeiro: Garamond.

Uziel, A. P. (2012). O melhor interesse da criança e o "mal menor": Quando os requerentes são gays. Scripta Nova (Barcelona), 16(395). Recuperado em 1 ago. 2013 de http://www.ub.edu/geocrit/sn/sn-395/sn-395-3.htm

Uziel, A. P., Mello, L., \& Grossi, M. P. (2006). Conjugalidades e parentalidades de gays, lésbicas e transgêneros no Brasil. Estudos Feministas, 14(2), 481-487.

Zambrano, E. (2006). Parentalidades "impensáveis": Pais/mães homossexuais, travestis e transexuais. Horizontes Antropológicos, 12(26), 123-147. 
Zambrano, E. (2015). As imposições simbólicas da diferença sexual e suas implicações na adoção por casais homossexuais. In F. Scorsolini-Comin, A. K. Pereira, \& M. L. T. Nunes (Orgs.), Adoção: legislação, cenários e práticas (pp. 51-62). São Paulo: Vetor.

\section{Sobre os autores}

Flávia Ximenes é psicóloga pela Universidade Federal do Triângulo Mineiro. Possui Pós-Graduação Lato Sensu pelo Programa de Residência Multiprofissional em Saúde da Criança da Pontifícia Universidade Católica de Campinas.

Fabio Scorsolini-Comin é doutor em Psicologia pela Faculdade de Filosofia, Ciências e Letras de Ribeirão Preto da Universidade de São Paulo, com pósdoutorado pela mesma instituição. Docente do Departamento de Psicologia e do Programa de Pós-graduação em Psicologia da Universidade Federal do Triângulo Mineiro. E-mail: fabioscorsolini@gmail.com

Certificamos que todos os autores participaram suficientemente do trabalho para tornar pública sua responsabilidade pelo conteúdo. A contribuição de cada autor pode ser atribuída como se segue: Flavia Ximenes contribuiu com a elaboração do projeto, coleta, análise de dados e redação do artigo. Fabio Scorsolini-Comin orientou o projeto de pesquisa que culminou no artigo, participando da análise dos dados, escrita e revisão. Ambos os autores são responsáveis pela redação final do texto. E-mail: flaviapsico.ximenes@gmail.com

Este artigo é derivado do trabalho de conclusão de curso da primeira autora, orientado pelo segundo autor, que recebeu o Prêmio Silvia Lane (8a edição, 2015), promovido pela Associação Brasileira de Ensino de Psicologia (ABEP).

Recebido em: 18/01/2017

Revisado em: 04/04/2017

Aceito em: 23/05/2017 